\title{
ORIGEM DA BACIA SEDIMENTAR COSTEIRA PERNAMBUCO-PARAÍBA
}

\author{
JANNES MARKUS MABESOONE ${ }^{1,2}$ e MARGARETH MASCARENHAS ALHEIROS ${ }^{2}$
}

\begin{abstract}
ORIGIN OF THE COASTAL SEDIMENTARY BASIN OF PERNAMBUCO-PARAÍBA. The Pernambuco-Paraíba sedimentary coastal basin is one of the less well known Atlantic marginal basins of Brazil. Due to the fact that exactly in this area the southern and equatorial Atlantic oceans at their opening did meet, its geological history is quite particular. Recent studies of revision of mapping and reinterpretation of data already published, including from adjacent areas, provided the following results: the Pernambuco-Paraíba Basin is formed by the subbasins Cabo, Olinda, Alhandra, and the southern part of Canguaretama, separated by structural lines, belonging to the suite of South Atlantic basins, after their lithic fill. The subbasins Natal and northern part of Canguaretama belong still to the Potiguar Basin. One of the last links between Brazil and Africa seems to have been the northern part of the so-called Transversal Zone, between Recife and João Pessoa, constituting a sill until the end of the Cretaceous; this sill was tilted towards the south and broke at about the Joano Pessoa-Mamanguape region. The faunal exchange between the South and Equatorial Atlantic, before Maastrictian, took place only during transgression phases; during regression phases the sill turned probably a landbridge which permitted the exchange of terrestrial flora and fauna between the two continents.
\end{abstract}

INTRODUÇÃo Em 1961, Beurlen resumiu, como um dos primeiros pesquisadores do assunto, as então novas idéias sobre o desenvolvimento paleogeográfico do Oceano Atlântico Sul a partir da separação dos continentes sul-americano e africano. Este autor já admitiu tal separação por um sistema de falhas que se abriram em forma de rifte tanto do sul como do norte, mais ou menos na mesma época, isto é, Eocretáceo. A partir das seqüencias estratigráficas nas bacias costeiras, então conhecidas ainda bastante precariamente, chegou à conclusão de que a ruptura final entre os dois continentes se realizou na porção que abrange a faixa entre Recife e João Pessoa, no Nordeste brasileiro, e a região Nigéria-Gabão, no lado africano. Contudo, esse trabalho não deu ênfase ằs implicações geotectônicas, como salientou o autor, mas essencialmente às relações estratigráficas e paleontológicas $\mathrm{e}$ às suas conclusōes paleogeográficas.

$\mathrm{Na}$ década seguinte, começou-se a interpretar os fenômenos da separação dos continentes à luz da nova tectônica global, tendo Asmus como um de seus maiores promotores no Brasil (Asmus \& Porto 1972). Asmus et al. (1973) reconheceram a importância da faixa costeira entre Recife e João Pessoa por constituir uma das mais importantes áreas envolvidas, principalmente quando da ruptura final. Em trabalhos posteriores, o mesmo autor e sua equipe (Asmus \& Ponte 1973, Ponte \& Asmus 1976, 1978, Asmus \& Carvalho 1977) enfatizaram essa importância, baseando-se em dados cada vez mais numerosos e significativos, admitindo, porém, que o problema ainda não estava completamente resolvido.

Outros autores têm-se preocupado com a abertura final do Oceano Atlântico, o lugar dos acontecimentos e a data mais ou menos precisa. Entre eles podemos mencionar Reyment $e t$ al. (1976) pelos dados paleontológicos, Sclater et al. (1977) baseando-se no Deep Sea Drilling Project e Rand (1976, 1978), com os dados geofísicos. Mais recentemente, existem ainda os trabalhos de Dias-Brito (1987), com dados essencialmente baseados em foraminíferos, e de Szatmari $e t$ al. $(1984,1987)$ e Françolin \& Szatmari (1987), com base nos resultados de estudos geofísicos pormenorizados. As conclusōes, porém, nem sempre foram as mesmas, por isso certas divergências permaneceram, principalmente pelo enfoque isolado dos dados.

\section{APRESENTAÇÃO DO PROBLEMA Permaneceu} então o problema do papel desempenhado pela bacia sedimentar costeira de Pernambuco e Paraíba, na fase final da abertura do Oceano Atlântico (Fig. 1).

Em primeiro lugar, devemos considerar as relações estratigráficas. $\mathrm{O}$ início da sedimentação sobre o embasamento pré-cambriano aconteceu no Aptiano com os detritos grossos da Formação Cabo. Depois de um curto hiato, depositaram-se os clásticos finos e calcários da Formação Estiva, no fim do Cenomaniano e início do Turoniano. Finalmente, a partir do Santoniano ou Campaniano, estabeleceu-se definitivamente a bacia sedimentar costeira na região entre Recife e João Pessoa. Comparando a época desses acontecimentos com os dos que se realizaram nas outras bacias sedimentares da margem atlântica brasileira, tanto mais para sul, como mais para norte (Asmus 1975), devemos concluir que a área em apreço foi a última a ser afetada pela reativação da Plataforma Sul-Americana, relacionada com a abertura do Oceano Atlântico e a separação dos continentes sul-americano e africano. Isto leva a supor que a separação e a ruptura final devem ter acontecido mais ou menos nesta área. Dentro das acumulações sedimentares, o pacote litológico mais interessante é o fosfato. Esta seqüência tèm sido objeto de numerosos estudos, até sedimentológicos (Menor 1975, Menor et al. 1977). Eles chegaram à conclusão de que se trata de um pacote de arenitos fosfáticos acumulados nas águas rasas da plataforma submersa e, em parte, retrabalhados. Dada a origem muito especial de rochas fosfáticas sedimentares, exigindo uma zona de ressurgência e, assim, condiçőes paleogeográficas especiais, esses sedimentos são da maior importância na interpretação da história geológica da área em questão. Infelizmente, não tem sido dada por outros autores a devida atenção a essa ocorrência.

Em segundo lugar, diversos dados foram apresentados pela Paleontologia. Importante é, nesse caso, a associação faunística em sua totalidade e suas relaçőes com outras partes do mundo, assunto já estudado por diversos autores (por exemplo, Reyment \& Tait 1972, Berggren \& Hollister 1974, Beurlen 1974, Noguti \& Santos 1972, Dias-Brito op. cit.). Os primeiros autores admitem o estabelecimento dos contatos entre as águas oceânicas do Atlântico Sul e Equatorial já plenamente a partir do Mesoturoniano. Beurlen (op. cit.), porém, apontando a semelhança faunística de espécies de águas rasas, durante a época da Formação Gramame (Maastrichtiano) com a África, só admite uma ligaçāo plena, com intercâmbio com a região caribeana, a partir da época Maria Farinha (Paleoceno). Segundo ele, aparentemente existia ainda uma ligação de tipo soleira ou mesmo continental entre Nigéria-Gabấo e o Nordeste do Brasil, até o fim do

1 Pesquisador 1-A do CNPq.

2 Departamento de Geologia, Universidade Federal de Pernambuco. Cidade Universitária, CEP 50732, Recife, PE, Brasil 
Cretáceo, na área do Recife e João Pessoa.

Também as pesquisas palinológicas efetuadas por Herngreen (1975) chegaram a conclusões que indicavam um intercâmbio de flora terrestre entre Brasil e África até no Neo-Senoniano (= Maastrichtiano). Herngreen afirma que as assembléias polínicas entre Brasil e África ocidental foram quase idênticas até o Albiano-Cenomaniano e que as do Neo-Senoniano guardam ainda muita semelhança. Concluiu também que o deslocamento dos blocos sul-americano e africano iniciou-se depois do Cenomaniano com maior intensidade.

Estudos mais pormenorizados da geofísica da área em apreço foram efetuados por Rand $(1976,1978)$, que chegou a interessantes conclusões sobre o comportamento estrutural da região, que podem ser assim resumidas: o modelo de ajuste dos continentes sul-americano e africano de Bullard et al. (1965), o mais usado, mostra uma grande área de superposição do Nordeste brasileiro e Nigéria, pela qual o delta do Níger não pode ser responsável. Assim, precisa-se admitir uma ligação mais demorada entre os continentes (crosta continental) e não apenas a possíveis fendas ou oscilações do nível do mar. Dessa maneira, Rand (1976) associou a ruptura final entre os dois continentes com o modelado landbridge ("ponte terrestre"). Os proto-oceanos Atlântico Sul e Atlântico Equatorial chegariam ao Nordeste em forma de riftes estreitos, começando a crescer pela expansão do assoalho oceânico no Rio Grande do Norte e em Alagoas. Isso foi possível graças a um sistema de falhas transversais (os lineamentos de Pernambuco e Paraíba, respectivamente), possibilitando a manutenção de uma ligação entre Pernambuco e Nigéria. Essas falhas transversais atuaram, assim, como falhas transcorrentes nos continentes. Só depois da separação final, essas falhas funcionaram como transformantes entre os trechos deslocados da Cordilheira Meso-Atlântica. O fraturamento já se tinha iniciado muito antes da ruptura final, como documentam as rochas vulcânicas nos dois lados do oceano. O bloco do Nordeste brasileiro não participou da expansão do assoalho oceânico e ficou saliente depois da ruptura final, não podendo mais voltar à posição original.

Mais indícios são fornecidos pelo fundo do Oceano Atlântico junto à região estudada. No que se refere a esse fundo oceânico, é apenas de importância o que fornece dados sobre as rochas antigas, do fim do Mesozóico e início do Cenozóico. Para tal, o Platô de Pernambuco, a elevação submarina no sopé continental descrito inicialmente por Kowsmann \& Costa (1976), é de grande importância. Esses autores chegaram a certas conclusões que ainda foram aperfeiçoadas por Alves \& Costa (1986), com os resultados resumidos da seguinte maneira: salvo alguns hiatos na deposição em forma de superfícies erosionais, a seqüência sedimentar depositada nesse platô é relativamente completa a partir do Aptiano, idade de acumulação da Formação Cabo. Contudo, como não existem poços perfurados nessa área, as conclusões devem ser tomadas com certa reserva, pois se basearam apenas em interpretações de perfis de reflexão sísmica.

Rand \& Mabesoone (1982) retomaram a idéia de que a última ligação entre a América do Sul e a África, no lado brasileiro, tenha sido uma "ponte terrestre", aproximadamente na região de Pernambuco-Paraíba, e de que o Platô de Pernambuco seria uma remanescência da mesma. Esta idéia, rejeitada por grande parte dos pesquisadores, está ganhando nova força (Bengtson 1986). Os argumentos contra se baseiam comumente num único aspecto do problema, seja apenas paleontologia, seja o caráter do fundo oceânico, por exemplo. $\mathrm{O}$ conjunto integrado de dados, porém, dificilmente permite negar a idéia de uma prolongada ligação entre os dois continentes, até pelo menos o Cretáceo mais superior, em forma de uma "ponte" ou uma soleira no fundo do oceano. De fato, os argumentos contrários invocam a presença de certos fenômenos (intercâmbio de fauna, por exemplo), enquanto justamente a ausência deles (falta de registro devido a uma ligação continental) parece ser mais importante.

Outros estudos baseados em geofísica feitos por Françolin \& Szatmari (1987) sugerem uma abertura do sistema rifte atlântico por uma rotação horária da América do Sul em relação à África, com um pólo de rotação localizado aproximadamente a $7^{\circ} \mathrm{S}$ e $39^{\circ} \mathrm{W}$. Uma das áreas fortemente afetadas foi a Bacia Potiguar, que mostra ainda um arcabouço tectônico conseqüente das forças em jogo. $\mathrm{O}$ modelo apresentado pelos autores indica a área entre Touros e João Pessoa como uma interrupção no rifte atlântico, ainda durante o Albiano, e a última área a ser separada.

CENÁRIO GEOLÓGICO Torna-se necessário, em primeiro lugar, apresentar a situação geológica e a coluna estratigráfica da faixa sedimentar costeira entre Natal e Alagoas, conforme dados mais recentemente obtidos (Fig. 2).

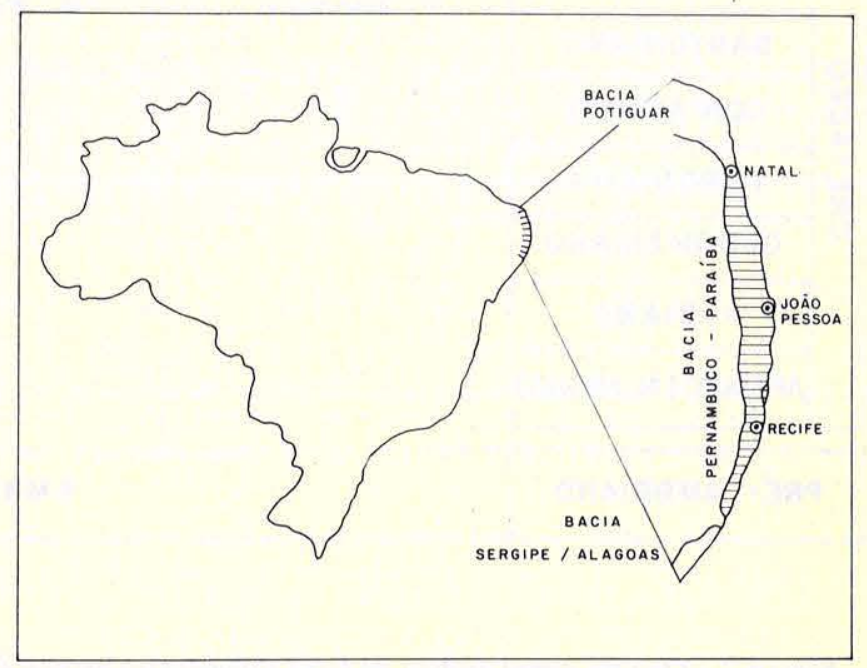

Figura 1 - Localização da faixa sedimentar costeira Pernambuco-Paraíba

A faixa aqui estudada é comumente chamada de Bacia Pernambuco-Paraíba enquanto a área sedimentar a sul de Natal é considerada como pertencente à Bacia Potiguar. De fato, essa área deixa-se subdividir em cinco sub-bacias, separadas entre si por importantes estruturas tectônicas, até o caráter litológico do embasamento cristalino, da seguinte maneira, de sul para norte:

- Bacia Sergipe-Alagoas

Alto de Maragogi-Barreiros

1. Sub-bacia Cabo.

Lineamento Pernambuco (ou Floresta)

2. Sub-bacia Olinda.

Falha de Goiana

3. Sub-bacia Alhandra.

Lineamento Paraíba (ou Patos)

4. Sub-bacia Canguaretama.

Falha de Cacerengo

5. Sub-bacia Natal.

Falha de Ceará-Mirim

- Plataforma Leste (da Bacia Potiguar) e Alto de Touros

O chamado Platô de Pernambuco encontra-se em frente da Sub-bacia Cabo (Fig. 3).

A subdivisão acima, baseada nos conhecimentos atuais das linhas estruturais, pode ser alterada à medida que surgirem dados mais pormenorizados, que estão sendo obtidos pelo levantamento aeromagnetométrico em execução pela Petrobrás. De qualquer maneira, a subdivisão em sub-bacias é uma hipótese de trabalho bastante satisfatória por refletir também as diferenças litológicas ao longo da Bacia Pernambuco-Paraíba, como é atualmente conhecida.

A unidade litoestratigráfica mais antiga encontrada é a 


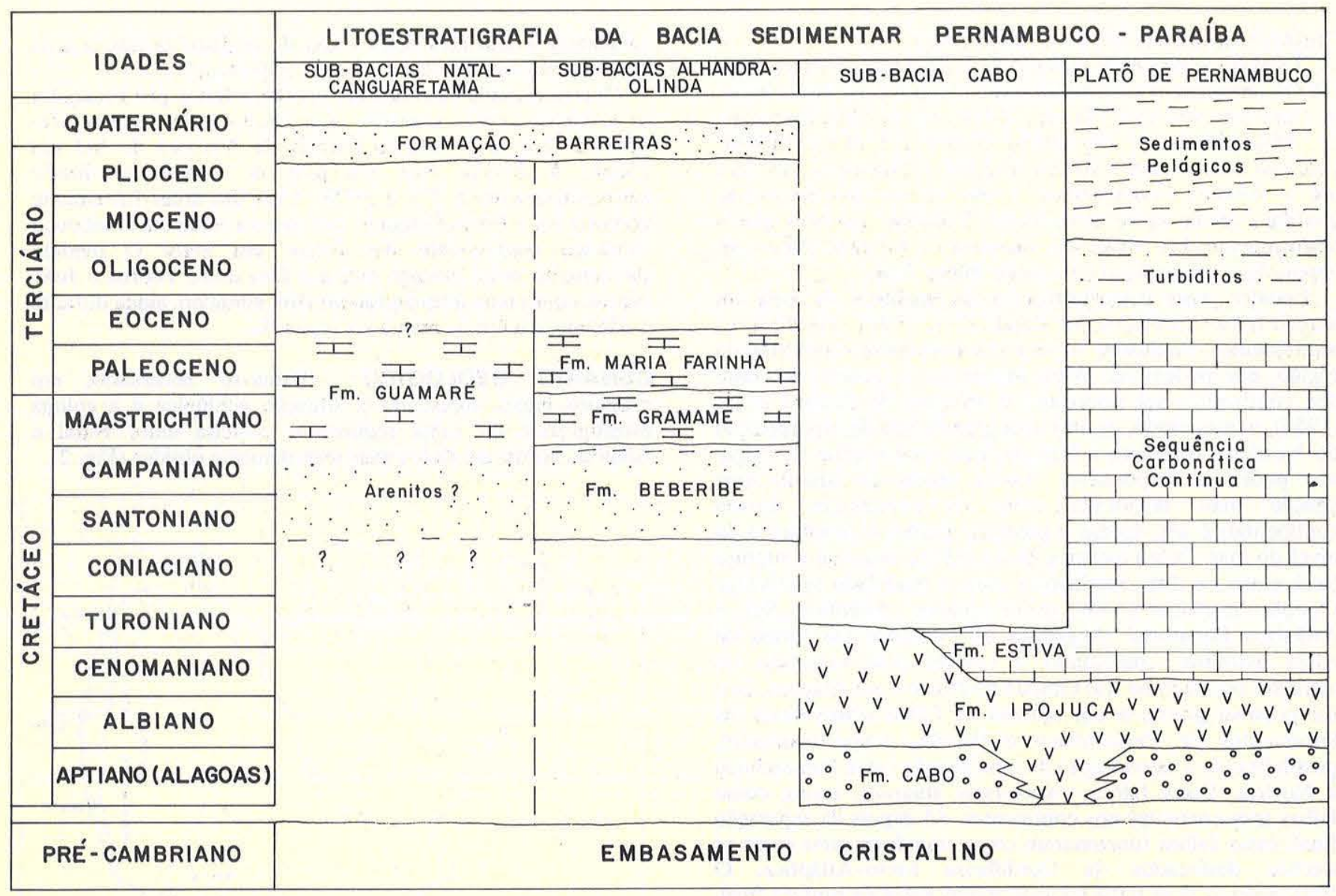

Figura 2 - Quadro estratigráfico da faixa sedimentar costeira Pernambuco-Paraíba, conforme dados de diversos autores

Formação Cabo, de idade Alagoas (Aptiano), estudada em detalhes por Alheiros (1987). Trata-se de uma seqüência de conglomerados até argilas. Corta e cobre esta seqüência o pacote de vulcanitos ácidos e alcalinos reunidos na Formação Ipojuca, datada de 90-114 Ma (Aptiano-Cenomaniano).

Acima das Formações Cabo e Ipojuca, encontra-se um pacote pouco espesso de clásticos relativamente finos e calcários conhecidos como Formação Estiva, para a qual dados paleontológicos mais recentes sugerem uma idade cenomaniana-eoturoniana. A seqüência parece ser mais espessa no Platô de Pernambuco (Alves \& Costa 1986).

Essas duas unidades sedimentares foram encontradas apenas na Sub-bacia Cabo e provavelmente no Platô Pernambuco. Na sub-bacia não foram identificadas unidades litoestratigráficas mais recentes do que as acima mencionadas.

A próxima seqüência acha-se nas sub-bacias Olinda, Alhandra e parte sul de Canguaretama, que se inicia com a Formação Beberibe, de idade santoniana-campaniana. É representada por uma sequëncia de clásticos arenosos grossos a finos, passando em direção da costa para arenitos calcíferos, chamados por alguns autores de Formação Itamaracá. No início do Maastrichtiano, a grande trangressão fez avançar a linha costeira, depositando a Formação Gramame, constituída por calcarenitos fossilíferos, localmente arenitos e calcários fosfáticos. A fase regressiva no Paleoceno é representada pelos calciclásticos finos e argilas calcíferas da Formação Maria Farinha. Com esta última unidade litoestratigráfica encerra-se o ciclo sedimentar da implantação da Bacia Pernambuco-Paraíba nas sub-bacias acima mencionadas.

No Platô de Pernambuco, a sedimentação parece ter acontecido mais continuamente conforme interpretações de
Alves \& Costa (1986). Segundo eles pode-se admitir uma deposição carbonática ininterrupta do Albiano-Cenomaniano (Formação Estiva) ao Eoceno Inferior (Formação Maria Farinha). Tal interpretação parece se justificar quando se considera a história geológica da região em sua totalidade.

Situação um pouco diferente encontra-se na parte norte da Sub-bacia Canguaretama e na Sub-bacia Natal. Comumente, esta área é considerada como pertencente à Bacia Potiguar e seu preenchimento, como também o pacote sedimentar da Plataforma Leste da mencionada bacia, é incluído na coluna estratigráfica da mesma (Souza 1982). Acima do embasamento pré-cambriano aparece um pacote arenítico mal conhecido e ainda sem nome (Queiroz et al. 1985, comparável com a Formação Açu?); cobrindo-o aparecem calcários provavelmente de idade maastrichtiana (Campanha 1974), que afloram próximo a Canguaretama, cuja idade parece indicar uma continuação dentro do Terciário Inferior. Petrograficamente, são muito semelhantes aos calcários que ocorrem nas regiōes de Macaíba e Ceará-Mirim mais para norte. Por isso, de acordo com a coluna estratigráfica de Souza (1982), esses calcários foram provisoriamente atribuídos à Formação Guamaré.

Depois da regressão do início do Terciário houve um longo período de erosão e desnudação, seguido no fim do Plioceno pela deposição da Formação Barreiras. Como esta fase é comum em todas as bacias sedimentares da margem atlântica nordestina, ela não foi mais considerada no presente trabalho.

Como peculiaridade, podemos ainda mencionar o fato de os calcários tipo Gramame ocorrerem apenas entre Recife e o vale do Rio Miriri (PB). Os calcários tipo Guamaré se estendem da região de Canguaretama até Natal. Entre o Rio 
Miriri e Canguaretama não foram encontradas rochas carbonáticas (Fig. 4), fato que já sugere uma certa separação entre as duas áreas.

Pelos dados atualmente disponíveis, principalmente pelo mapa gravimétrico, a Bacia Pernambuco-Paraíba, excetuando-se a Sub-bacia Cabo, mostra-se como um homoclinal ao longo de toda sua extensão desde o contato com o embasamento cristalino até a plataforma submersa. A espessura de sedimentos varia entre 1.000 e $1.500 \mathrm{~m}$, mergulhando suavemente para leste, podendo atingir 3.000-4.000 m sobre o Platô de Pernambuco. Apenas na região de Cabo, esse homoclinal é truncado por um gráben alongado de direção NNE (o chamado Gráben de Cupe ou Cabo).

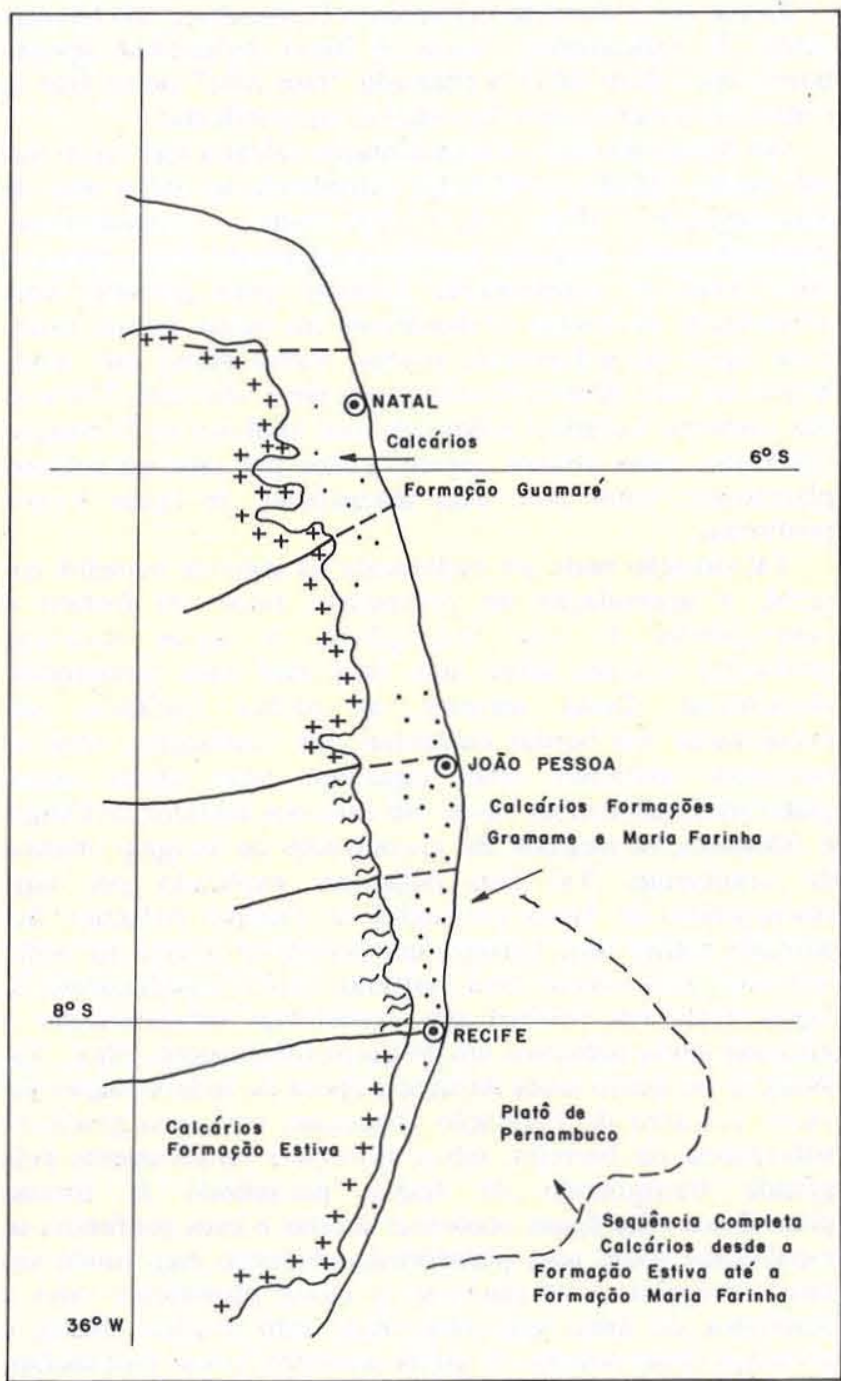

Figura 3 - Subdivisão geológica-estrutural da faixa sedimentar costeira Pernambuco-Paraíba

\section{OCEANO ATLÂNTICO SUL E EQUATORIAL}

Abertura Como geralmente se admite, a abertura do Oceano Atlântico se deu de sul para norte com a formação do Atlântico Sul, e de norte para sul e sudeste formado o Atlântico Norte e Equatorial.

Segundo dados mais recentes de Szatmari et al. (1984, 1987), porém o Oceano Atlântico Sul se abriu devido a um movimento de rotação horária do continente sul-americano em relação ao africano. Esta rotação, que diferenciou segmentos de extensāo e compressão ao longo da margem continental, fez abrir o grande rifte $\mathrm{S}-\mathrm{N}$ até o Reconcâvo-Tucano, com desvios para NE nas bacias de Santos-Campos e Sergipe-Alagoas, provavelmente causadas por linhas estruturais no embasamento. Na margem equatorial, a rotação causou uma compressão e, da região nordeste para leste, estruturas complexas, tanto de extensão como de compressão.

O resultado foi que ficou no Nordeste oriental, na região de Pernambuco, Paraíba e parte oriental do Rio Grande do Norte uma área de ligação entre o Brasil e a África, como também provavelmente uma outra, localizada aproximadamente no alto estrutural do Arco Ferrer-Urbano Santos. Entre essas duas ligações abriu-se um pequeno rifte tríplice, onde um dos braços é a Bacia Potiguar e outro se estende pela Fossa de Benuê na África. A abertura das bacias de Barreirinhas e as outras mais para o norte aconteceram mais tarde com a mudança do pólo de rotação.

Conforme Szatmari et al. (op. cit.), a abertura total se realizou no Albiano-Cenomaniano. Em épocas posteriores porém, que se tenta interpretar como conseqüência da aproximação da África com a Europa, surgiram diversos pulsos de compressão $\mathrm{N}-\mathrm{S}$, principalmente no Neocretáceo. Durante tais pulsações, a África e a América do Sul se aproximaram em alguns lugares com a provável formação de

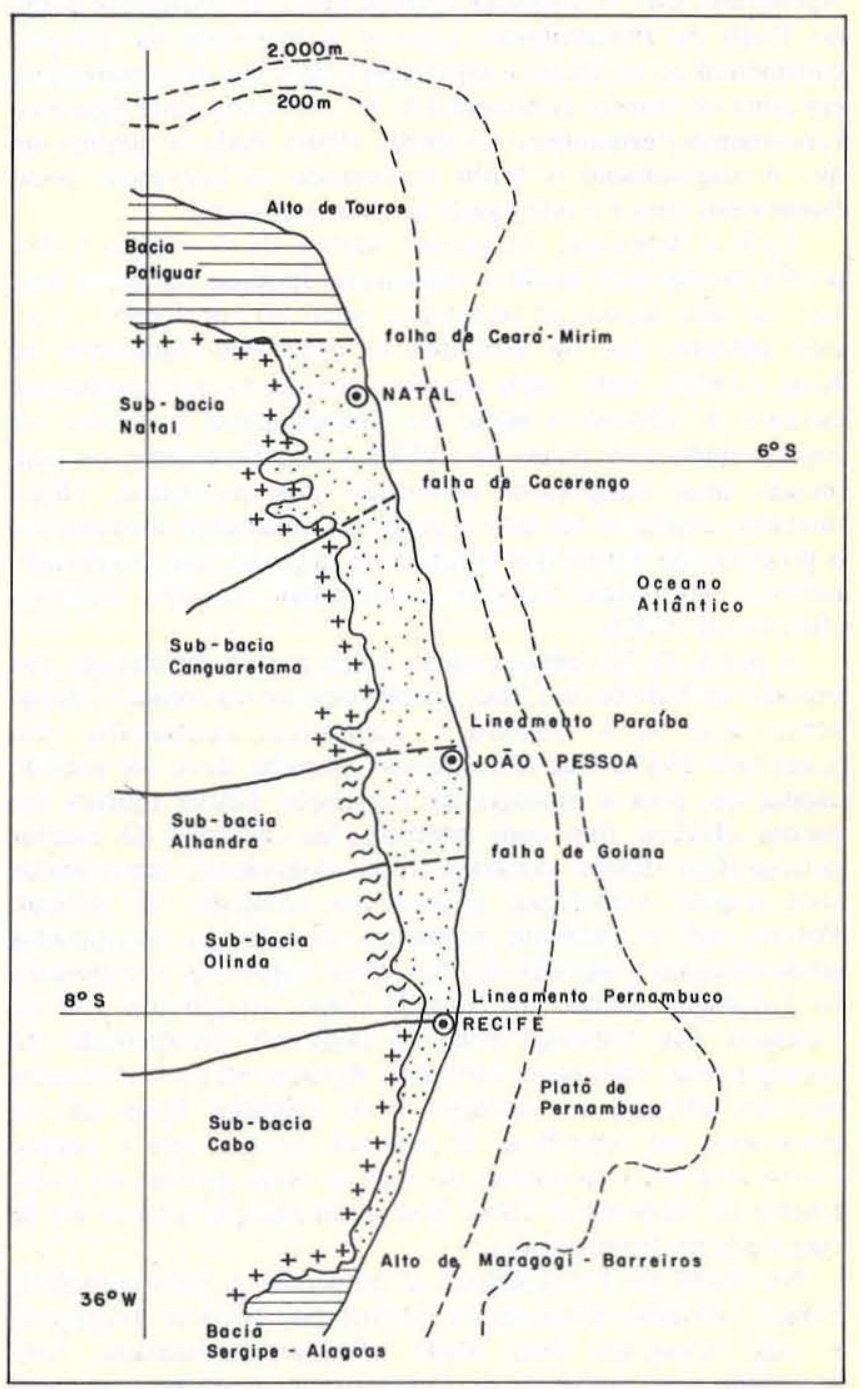

Figura 4 - Ocorrências dos calcários na faixa sedimentar costeira Pernambuco-Paraíba 
ligaçōes até terrestres - isto aconteceu com certeza no chamado Alto Atlântico, na região de Camocim (CE), e quase certamente também na região de Pernambuco-Paraíba (Françolin, com. verbal).

Assim, o movimento de rotação horária da América do Sul em relação à África foi a causa principal da formação das bacias sedimentares da margem atlântica e de suas estruturas, e também teve conseqüências no interior nordestino. Neste contexto, a bacia sedimentar Pernambuco-Paraíba, excetuando-se a Sub-bacia Cabo, ocupa lugar especial por não ser uma bacia rifte, mas apenas homoclinal.

Bacia Pernambuco-Paraíba A abertura da parte sul do Oceano Atlântico até o Lineamento Pernambuco formou com certa rapidez uma fossa bastante profunda, como atesta o furo de Cupe (PE) na Sub-bacia Cabo, onde o embasamento cristalino ainda não foi atingido, a uma profundidade de 3.000 $\mathrm{m}$. Essa fossa profunda foi preenchida com clásticos de leques aluviais e de lagos registrados também no Platô de Pernambuco.

Cortando, intercalando e até cobrindo-esse pacote de clásticos variados, encontra-se a seqüência vulcânica da Formação Ipojuca, com idades radiométricas de 90 a $114 \mathrm{Ma}$ (Vandoros \& Valarelli 1976). Com seus derrames, diques, soleiras e plugues de riólitos, andesitos, basaltos e traquitos, além do conhecido granito alcalino do Cabo de Santo Agostinho, este vulcanismo aparece tanto no continente como no Platô de Pernambuco. Liga-se à tectônica da margem continental ao se iniciar a separação e deve ter-se manifestado em zona de fratura continental E-W, provavelmente ligada ao Lineamento Pernambuco (Almeida 1986). Pode-se admitir até que o magmatismo se tenha processado na interseção desse lineamento com a fenda ligada ao rifteamento sul.

Após a deposição do pacote clástico da Formação Cabo, porém perdurando ainda o vulcanismo Ipojuca, há agora uma fase de não-deposição registrada tanto no continente, como mar adentro, que foi atribuída ao ciclo Pós-Gondwana de King (1967). Este ciclo erosivo aconteceu provavelmente durante o Albiano e início do Cenomaniano, e parece ter representado uma pausa na tectônica do rifteamento, ou pelo menos uma temporária atenuação dos processos. Neste intervalo supõe-se ter sido o próprio rifteamento terminado e o processo de deriva dos continentes iniciado, fato constatado também em outras margens continentais do tipo atlântico (Brice et al. 1983).

A partir do Neocenomaniano o mar parece ter iniciado sua invasẩo na Sub-bacia Cabo, aparentemente no começo apenas sobre uma faixa costeira e plataforma continental rasa (Laurindo 1983). Tal transgressão marinha deve ter sofrido oscilaçōes, pois a litologia da Formação Estiva mostra um pacote clástico fino com intercalaçōes calcárias. $\mathrm{O}$ caráter petrográfico desses calcários (ferro-dolomitos), intercalados com argilas vermelhas, sugere um ambiente de sabkha. Porém, até o presente momento não foram encontradas ainda camadas evaporíticas finas nesta seqüência. A espessura da Formação Estiva, no furo de Cupe, atingiu uns $100 \mathrm{~m}$. Contudo, sua presença atual só pode ser comprovada em subsuperfície, com raras exceções. Apenas em poucos lugares restritos afloram os calcários e os clásticos finos nâo se preservam em superfície. É possível, porém, que o pacote Estiva seja mais freqüente do que se pode provar, na parte emersa da Sub-bacia Cabo. Sua sedimentação parece ter se encerrado no Eoturoniano.

No Platô de Pernambuco, a seqüência é mais completa. Foram coletadas amostras de calcário por meio de dragagem, e elas acusaram uma idade albiana/cenomaniana, com deposição num ambiente de plataforma rasa até lagunar, com boa circulação e com energia moderada a alta (Asmus \& Carvalho 1977). Ainda mais: os perfis sísmicos sugerem uma sedimentação carbonática contínua até o início do Eoceno, incluindo desta maneira também as formações Gramame (Maastrichtiano) e Maria Farinha (Paleoceno-Eoceno), das sub-bacias Olinda, Alhandra e Canguaretama, mais para norte. Isso permite supor que também nessas últimas sub-bacias a sedimentação se deu de sul para norte, estando ligada à abertura do Oceano Atlântico Sul.

A Formação Beberibe, de idade campaniana-santoniana, é constituída por clásticos grossos a finos, de fácies fluvial entrelaçada e flúvio-lagunar a flúvio-deltaica. Mais para o litoral, o sistema deposicional desta formação se torna de plataforma rasa a costeira, com arenitos calcários. Há indícios, ainda não comprovados por perfurações, de que na base da unidade acha-se um pacote conglomerático presente nos baixos da superfície pré-Beberibe, que corresponderia a depósitos de leques aluviais associados.

Desde que a norte do Lineamento Pernambuco não há mais sinais de rifteamento, sendo a bacia sedimentar apenas homoclinal, deve faltar a chamada "fase rifte" nessa área e, conseqüentemente, seus depósitos correspondentes.

No Maastrichtiano, a sedimentação calcária tem início nas sub-bacias Olinda e Alhandra estendendo-se até o alto de Mamanguape (PB) na Sub-bacia Canguaretama. Aparentemente, além da grande transgressāo dessa época, a área tinha se aprofundado bastante para permitir uma acumulação de rochas carbonáticas em águas menos rasas. Dois tipos de sedimentos, porém, fazem supor que ainda houve um alto dentro do oceano em plena abertura. Trata-se das camadas fosfáticas e dos calcários argilosos da Formação Gramame, estes últimos caracterizados por uma microfauna planctônica junto com uma macrofauna de águas menos profundas.

Tal situação pode ser esclarecida da seguinte maneira: em geral, a acumulação de sedimentos ricos em fosfato é conseqüência de uma ressurgência de águas oceânicas profundas e frias, sobre uma área mais rasa, comumente plataformal. Desta maneira, as rochas fosfáticas são encontradas nas bordas ocidentais dos continentes, onde as correntes marinhas frias espalham suas águas sobre plataformas submersas rasas. No caso dos fosfatos de Olinda e Alhandra, os mesmos são encontrados na margem oriental do continente. Tal fato pode ser explicado por uma ressurgência de águas profundas do Oceano Atlântico Sul subindo contra uma barreira em forma de soleira ou ponte terrestre, num oceano ainda estreito, com o espalhamento de águas ricas em fósforo nos continentes sul-americano e africano ainda próximos um do outro (Mabesoone 1981). Tal situação perdurou ainda durante a época de sedimentação das fácies calcárias da Formação Gramame, com uma gradativa subsidência da barreira, talvez reforçada relativamente pela grande transgressão da época, permitindo às formas planctônicas das águas oceânicas abertas e mais profundas se espalharem sobre uma plataforma submersa, com fundo um tanto irregular, misturando-se a fauna planctônica com a bentônica da área mais rasa. Esse fato implica, assim, a presença dessa soleira ou ponte terrestre, como propuseram Rand \& Mabesoone (1982).

A fase regressiva do início do Terciário é representada pelos calcários detríticos da Formação Maria Farinha, que encerra o ciclo sedimentar da fase de abertura do Oceano Atlântico. Nesta época, a última ligação entre os continentes sul-americano e africano já tinha desaparecido, bem como as formas faunísticas de água rasa iguais entre as partes norte e sul da costa brasileira, com afinidades com a América do Norte. Com a retirada do mar, as camadas carbonáticas lamíticas chegaram aos poucos a aflorar, tornando-se argilas residuais. A última camada de sedimento dessa fase deposicional é uma areia de praia ainda encontrada em alguns lugares. Agora inicia-se um novo período de erosão e desnudação, que na parte emersa da Bacia Pernambuco-Paraíba perdura até o fím do Plioceno. 
Parte oriental da Bacia Potiguar A Bacia Potiguar, que limita a área aqui estudada a NW, é a mais oriental das bacias da margem equatorial. A parte mais profunda dessa bacia constitui-se de um gráben de direção SW-NE, preenchido pelos clásticos da fase rifte e pelos sédimentos carbonáticos das fases proto-oceânica e marinha transgressiva e regressiva. A extensão oriental inclui o chamado Alto de Touros e é comumente considerada como mostrando a mesma seqüência litológica com seu início mais tardio. Atualmente, porém, essa consideração não é mais aceita sem crítica e aparentemente os depósitos ali encontrados são bem mais jovens do que se supôs anteriormente (vide, por exemplo, Damasceno et al. 1984, Srivestava \& Corsino 1984). Contudo, a comprovação dessas suposiçōes ainda não ocorreu pela falta de dados suficientes. Apenas existem as suposições de Françolin \& Szatmari (1987), que apresentam argumentos dessa faixa entre João Pessoa e o Alto de Touros ter sido uma das últimas ligações entre o Brasil e a África.

Assim, a parte oriental da Bacia Potiguar, também conhecida como Plataforma Leste, com sua extensão submarina, parece destacar-se da bacia como parte diferente. Também nẫo foi rifteada e constitui uma área homoclinal parecida com a de Pernambuco-Paraíba. Conforme Cordani et al. (1984), o Alto de Touros é provavelmente uma continuação da Zona Geanticlinal Nova Floresta dentro do Maciço pré-cambriano de Caldas Brandão-São José do Campestre.

Os calcários da Bacia Potiguar sempre foram considerados de idade santoniana-campaniana (a chamada Formação Jandaíra), porém em nenhum trabalho a respeito como, por exemplo, de Souza (1982), foi feita menção à parte oriental da bacia. Aparentemente, esta área não se encaixou no padrão geral da Bacia Potiguar e a interpretação ficou duvidosa. Assim, os únicos dados a nossa disposição são os de Beurlen (1970, p. $343-344)$, de que os calcários da região de Natal deveriam ter uma idade maastrichtiana, podendo chegar a Paleoceno ou até mesmo a Eoceno. Isso foi em parte confirmado pelos estudos de Campanha (1974). Esta interpretação adicionada às de Damasceno et al. (1984) e de Srivastava \& Corsino (1984) permite incluir esses calcários na Formação Guamaré de Souza (1982). Neste caso, esta unidade litoestratigráfica ocorreria também em superfície.

Tomando as suposições acima como as mais prováveis, fato que se coaduna com a seqüência lógica de eventos, a seção estratigráfica das sub-bacias Natal e Canguaretama, até o Alto do Mamanguape, representaria uma última fase na abertura do Oceano Atlântico. Isso colocaria em dúvida a interpretação de Feitosa \& Feitosa (1986) sobre um pacote contínuo de idade campaniana desde João Pessoa até Natal, e a conseqüente superposição das bacias Pernambuco-Paraíba e Potiguar.

Tendo havido uma sedimentação procedente do sul na área das sub-bacias Olinda, Alhandra e parte sul de Canguaretama, e provavelmente do norte nas sub-bacias Natal e parte norte de Canguaretama, deve ter existido uma área topograficamente mais alta na região de Mamanguape (PB). Este alto seria a última ligação com a África no Nordeste brasileiro, que existiu, depois que a soleira se basculou para sul até romper definitivamente em sua parte mais setentrional.

EVOLUÇÃO TERCIÁRIA-QUATERNÁRIA Após a regressão definitiva do mar na regiâo estudada, provavelmente no início do Eoceno, a história geológica da região torna-se mais uniforme. Em primeiro lugar, há até o fim do Plioceno um longo período de erosão e denudação, porém com acumulação de algum sedimento na plataforma continental e no Platô de Pernambuco. Depois vem o episódio da sedimentação da Formação Barreiras e, por fim, segue-se o desenvolvimento quaternário com registros bem preservados ao longo da costa e no relevo da regiâo.

As unidades geoestruturais têm-se estabelecido até o fim do Paleoceno; depois desse período, a faixa total se comportou como uma unidade, manifestada pela onipresença das superfícies de erosão e denudação, e pelos depósitos da Formação Barreiras, com poucas e restritas exceções (a quase completa ausência desse pacote na Sub-bacia Cabo). Também a evolução quaternária mostra a uniformidade das feições ao longo da costa inteira.

CONCLUSÕES Integrando agora as idéias lançadas sobre a abertura do Oceano Atlântico e a história geológica da bacia sedimentar costeira Pernambuco-Paraíba, incluindo as suposições bem fundamentadas de Rand $(1976,1978)$ e Françolin \& Szatmari (1987), podemos chegar às seguintes conclusões:

1. Conforme dados estratigráficos e estruturais, a Bacia Pernambuco-Paraíba pertence a seqüência de bacias marginais do Oceano Atlântico Sul e constitui-se das sub-bacias Cabo, Olinda, Alhandra e parte sul de Canguaretama, com uma sedimentação em duas faces principais, entre o Aptiano e o Eoceno Inferior.

2. Conforme o mesmo tipo de dados, as sub-bacias Natal e parte norte de Canguaretama constituem uma extensão da Bacia Potiguar, porém de idade mais recente.

3. Essas áreas não são rifteadas, com exceção da sub-bacia Cabo, constituindo apenas homoclinais, sendo assim semelhantes entre si.

4. Pela compressão que aproximou o Brasil da África, existiu, até provavelmente o fim do Cretáceo, um alto entre os dois lados do Oceano Atlântico em forma de soleira ou, talvez, ponte terrestre emersa.

5. Esta soleira, durante seu rebaixamento, basculou para sul, permitindo à sedimentação do rifte sul-atlântico chegar até a regiāo a norte de João Pessoa (Formação Gramame).

6. O intercâmbio de faunas do Atlântico Sul com o Equatorial em épocas anteriores, como, por exemplo, no Albiano, sempre ocorreu durante fases transgressivas com um nível de mar alto. Este mar inundou temporariamente as soleiras ou eventuais ligaçōes terrestres entre os dois continentes.

7. Nas épocas regressivas deve ter existido uma ligação continental verdadeira, permitindo o intercâmbio de flora e fauna continentais entre ambos os lados.

8. A Sub-bacia Cabo, única parte rifteada, constitui assim a extremidade setentrional da Bacia Sergipe-Alagoas.

9. As outras sub-bacias, mesmo as do Rio Grande do Norte, parecem pertencer a um único conjunto de bacia sedimentar homoclinal, com um alto na região de Mamanguape (PB). A inclinação a partir do mesmo para sul e para norte, provocou diferenças no registro litológico e estratigráfico entre as duas áreas.

10. Só a partir do início do Eoceno, a Bacia Pernambuco-Paraíba e a parte sub-oriental da Bacia Potiguar ficaram definitivamente estabelecidas começando-se a partir de então uma história geológica comum, mais sentida em sua parte continental.

Agradecimentos $\mathrm{O}$ presente trabalho é parte do resultado final do sub projeto "Revisão geológica da faixa sedimentar costeira de Pernambuco, Paraíba e Rio Grande do Norte, e do seu embasamento", da fase teste do PADCT, com financiamento pela Finep, para o qual os autores expressam seus sinceros agradecimentos. Esses agradecimentos se estendem também aos comentários e novos dados fornecidos na revisão do manuscrito; e ao geólogo J.B.L. Françolin, pelos esclarecimentos a respeito dos novos estudos em execução. 


\section{REFERÊNCIAS BIBLIOGRÁFICAS}

ALHEIROS, M.M. 1987. Caracterização sedimentológica da Formaçâo Cabo-Pernambuco. Recife, 99p. (Dissertação de Mestrado, Univ. Fed. Pernambuco)

ALMEIDA, F.F.M. 1986. Distribuição regional e relaçōes tectônicas do magmatismo pós-paleozóico no Brasil. Rev. Bras. Geoc., 16:325.349.

ALVES, E.C. \& COSTA, M.P.A. 1986. Interpretação sismo-estratigráfica da porção norte do Platô de Pernambuco e suas possíveis correlações com a Bacia Pernambuco-Paraíba. In: CONGR. BRAS. GEOL., 34, Goiânia, 1986. Anais... Goiânia, SBG. v. 1, p. 286-297.

ASMUS, H.E. 1975. Controle estrutural da deposição mesozóica nas bacias da margem continental brasileira. Rev. Bras. Geoc., 5:160-175.

ASMUS, H.E. \& CARVALHO, J.C. 1977. Condicionamento tectônico da sedimentação nas bacias marginais do Nordeste do Brasil (Sergipe/Alagoas e Pernambuco/Paraíba). In: PETROBRÁS. Aspectos estruturais da margem continental leste e sudeste do Brasil. Rio de Janeiro. Cenpes/Dintep. p. 7-24. (Série Projeto REMAC 4).

ASMUS, H.E. \& PORTO, R. 1972. Classificação das bacias sedimentares brasileiras segundo a tectônica de placas. In: CONGR. BRAS. GEOL., 26, Belém, 1972. Anais... Belém. SBG. v. 2 , p. 67-90.

ASMUS, H.E. \& PONTE, F.C. 1973. The Brazilian marginal basins. In: NAIRN, A.E. \& STEHLI, F.G. eds. The ocean basins and margins: v. I - The South Atlantic. New York, Plenum Press. p. 87-133.

ASMUS, H.E.; CARVALHO, J.C.; ZEMBRUSCKI, S. 1973. Evolução do Atlântico Sul e a área Recife--João Pessoa. In: CONGR. BRAS. GEOL., 27, Aracaju, 1973. Separata (resumo Simp. Geodinâmica).

BENGSTON, P. 1986. Middle Cretaceous stratigraphy and paleogeography of the Nordeste Block in northeastern Brazil. Cretaceous Research, 47 p. (manuscript).

BERGGREN, W.A. \& HOLLISTER, C.D. 1974. Paleogeography, paleobiogeography and the history of circulation in the Atlantic Ocean. In: HAY, W.W. ed. Studies in paleo-oceanography. Soc. Econ. Paleont. Min., Spec. Publ. 20, p. 126-186.

BEURLEN, K. 1961. Die Kreide im Küstenbereich von Sergipe bis Paraiba do Norte (Brasilien). Zeitschr. deutsch. geol. Ges., 112:378-384.

BEURLEN, K. 1970. Geologie von Brasilien. Berlin. Gebr. Borntraeger. 444 p. (Beiträge zur regionalen Geologie der Erde 9).

BEURLEN, K. 1974. Die geologische Entwicklung des Atlantischen Ozeans. Geotekt. Forschungsh., 46:1-69.

BRICE, S.E.; COCHRA, M.D.; PARDO, G.; EDWARDS, A.D. 1983 Tectonic sedimentation of the South Atlantic rift sequence: Cabinda Angola. Tulsa (Oklahoma), Am. Assoc. Petroleum Geol., p. 5-18. (Memoir 34).

BULLARD, E.C.; EVERETT, J.E.; SMITH, A.G. 1965. The fit of the continents around the Atlantic. Royal Soc. (London) Philos. Transactions, Ser. A, 258(1088):4-51.

CAMPANHA, V.A. 1974. Posição estratigráfica do calcário Miriri, Paraiba, Brasil. Porto Alegre, 184 p. (Dissertação de Mestrado, Univ. Fed. Rio Grande do Sul).

DAMASCENO, J.M.; FARIAS, C.C.; LIMA, M.S.; MABESOONE, J.M.; OLIVEIRA, L.D.D.; OLIVEIRA, M.I.M. 1984. Sedimentos da faixa Afonso Bezerra-Macaíba (borda meridional da Bacia Potiguar, RN); 6. Interpretação estratigráfica. In: SIMP. GEOL. NORDESTE, 11, Natal, 1984. Atas... Recife, Núcleo Nordeste SBG. Bol. 9, p. 135-141.

DIAS-BRITO, D. 1987. A Bacia de Campos no Mesocretáceo: uma contribuição à paleoceanografia do Atlântico Sul primitivo. Rev. Bras. Geoc. 17:162-167.

FEITOSA, E.C. \& FEITOSA, F.A.C. 1986. Consideraçôes sobre a ligação Bacia Potiguar-Bacia costeira Pernambuco-Paraíba. In: UFPE, DEPT. ENG. MINAS, Estudos geológicos. Recife, p. 71-78. (Série B, Estudos de Pesq. 8).

FRANÇOLIN, J.B.L. \& SZATMARI, P. 1987. Mecanismo de rifteamento da porção oriental da margem norte brasileira. Rev. Bras. Geoc., 17:196-207.

HERNGREEN, G.F.W. 1975. Palynology of Middle and Upper Cretaceous strata in Brazil. Mededelingen Rijks Geol. Dienst, Nw. Serie 26(3):39-91.
KING, L.C. 1967. The Morphology of the Earth, 2 ed. Edinburgh and London, Oliver and Boyd, 726 p.

KOWSMANN, R.O \& COSTA, M.P.A. 1976. Estratigrafia sísmica do Platô de Pernambuco. Rev. Bras. Geoc., 6:95-101.

LAURINDO, A.M.O. 1983. Estudo faciológico dos carbonatos da Formação Cabo, Pernambuco. Recife, 91 p. (Dissertação de Mestrado, Univ. Fed. Pernambuco).

MABESOONE, J.M. 1981. Modelo deposicional dos fosforitos de Pernambuco. In: UFPE/DEPTO. GEOL. Estudos geológicos. Recife, p. 17-26. (Série B, Estud. Pesq. 4)

MENOR. E.A. 1975. La sédimentation phosphatée, pétrographie, minéralogie et géochimie des gisements de Taiba (Sénégal) e d'Olinda (Brésil). Strasbourg, 153 (Thèse doct. ing., Univ. Louis Pasteur, Strasbourg).

MENOR, E.A.; DANTAS, J.R.A.; SOBRINHO, A.C.P. 1977. Sedimentação fosfática em Pernambuco e Paraíba: revisão e novos estudos. In: SIMP. GEOL. NORDESTE, 8, Campina Grande, 1977. Atas... Recife, SBG. Núcleo Nordeste. Bol. 6, p. 1-27

NOGUTI, I \& SANTOS, J.F. 1972. Zoneamento preliminar por foraminíferos planctônicos do Aptiano ao Mioceno na plataforma continental do Brasil. Bol. Téc. Petrobrás, 15:265-283.

OJEDA, H.A.O. \& FUGITA, A.M. 1974. Bacia Sergipe/Alagoas: geologia regional e perspectivas petrolíferas. In: CONGR. BRAS GEOL., 28, Porto Alegre, 1974. Anais... Porto Alegre, SBG. v. 1, p. $137-158$.

PONTE, F.C. \& ASMUS, H.E. 1976. The Brazilian marginal basins: current state of knowledge. Anais Acad. bras. Ciênc., 48 (Supl.):215-239.

QUEIROZ, M.A.; MACEDO, J.W.P.; DE ROOY, C.; ARAÚJO, T.C.M. 1985. Contribuição da geofísica ao mapeamento geológico da área de Canguaretama, RN. In: UFRN/DEPTO. GEOL. Natal, p. 58-67. (Bol. 10).

RAND. H.M. 1976. Estudos geofísicos na faixa litorânea ao sul do Recife. Recife, 112 p. (Tese Livre-Docência, Univ. Fed. Pernambuco).

RAND, H.M. 1978. Análise gravimétrica e magnetométrica da estrutura superficial da faixa costeira do Nordeste brasileiro. In: CONGR. BRAS. GEOL., 30, Recife, 1978. Anais... Recife, SBG. v. 5, p. 2336-2346.

RAND, H.M. \& MABESOONE, J.M. 1982. Northeastern Brazil and the final separation of South America and Africa. Paleogeogr., Palaeoclimat., Palaeoecol., 38:163-183.

REYMENT, R.A. \& TAIT, E.A. 1974. Biostratigraphical dating of the early history of the South Atlantic Ocean. Philos Trans. Royal Soc. London (B) 264:55-95.

REYMENT, R.A.; BENGSTON, P.; TAIT, E.A. 1976. Cretaceous transgressions in Nigeria and Sergipe-Alagoas. Anais Acad. Bras. Ciências, 48 (Supl.):253-264.

SCLATER, J.G.; HELLINGER, S.; TAPCOTT, C. 1977. The paleobathymetry of the Atlantic Ocean from the Jurassic to the Present. J. Geol., 85:509-522.

SRIVASTAVA, N.K. \& CORSINO, A.R. 1984. Os carbonatos de Touros: petrografia e estratigrafia. In: SIMP. GEOL. NORDESTE, 11, Natal, 1984. Atas... Recife, Núcleo Nordeste SBG. Bol. 9, p. 165-176.

SOUZA, S.M. 1982. Atualização da litoestratigrafia da Bacia Potiguar. In: CONGR. BRAS. GEOL., 32, Salvador, 1982. Anais... Salvador, SBG. v. 5 , p. $2392-2406$.

SZATMARI, P.; CONCEIÇÃO, J.C.L.; LANA, M.S.; MILANI, E.J.; LOBO, A.P. 1984. Mecanismo tectônico do rifteamento sul-atlântico. In: CONGR. BRAS. GEOL., 33, Rio de Janeiro, 1984, Anais... Rio de Janeiro, SBG. v. 4, p. 1589-1601.

SZATMARI, P.; FRANÇOLIN, J.B.L.; ZANOTTO, O.; WOLFF, S. 1987. Evolução tectônica da margem equatorial brasileira. Rev. Bras. Geoc., 17:180-188.

VANDOROS, P. \& VALARELLI, J.V. 1976. Geologia da região do Cabo de Santo Agostinho, PE. In: CONGR. BRAS. GEOL., 29, Ouro Preto, 1976. Res. Trab... Belo Horizonte, SBG. p. 19.

MANUSCRITO 532

Recebido em 13 de abril de 1988 Revisão aceita em 13 de outubro de 1988 